Abstract

\title{
Development of a Confocal Laser Doppler Flowmeter Using Optical Feedback Interferometry Techniques ${ }^{\dagger}$
}

\author{
Carlos Yáñez * and Santiago Royo * \\ Universitat Politècnica de Catalunya, BarcelonaTech, 08034 Barcelona, Spain \\ * Correspondence: carlos.rene.yanez@upc.edu (C.Y.); santiago.royo@upc.edu (S.R.) \\ + Presented at the 5th International Symposium on Sensor Science (I3S 2017), Barcelona, Spain, \\ 27-29 September 2017.
}

Published: 19 December 2017

We are presenting a novel confocal laser Doppler flowmeter based on optical feedback interferometry. The system determines the Doppler shift occurring in an $830 \mathrm{~nm}$ laser diode when a small portion of the emitted light is back-reflected into the laser cavity after interacting with the particles of an emulsion flowing into a capillary; this second field modulates the laser emission and the changes in the optical output power are used to determine the Doppler frequency regarding the flow velocity. The confocal setup employs a diaphragm to delimit the beam diameter and reduce the phase noise and the out-of-focus particle effect, allowing real-time measurements of the velocity at which the particles are flowing in a very specific region inside the capillary. We demonstrate the benefits of this technique comparing the Doppler spectrum obtained without the confocal arrangement against a confocal measurement.

Conflicts of Interest: The authors declare no conflict of interest.

(C) 2017 by the authors. Licensee MDPI, Basel, Switzerland. This article is an open access article distributed under the terms and conditions of the Creative Commons Attribution (CC BY) license (http://creativecommons.org/licenses/by/4.0/). 